\title{
Extensive Cannon Ball Metastases-A Case Study of a 49-Year-Old Bulgarian Male
}

\author{
Kiran Kumar \\ Department Of Internal Medicine, Gulf Medical College Hospital and Research Centre, Ajman, UAE \\ Email: drkiran_k@yahoo.com
}

Received 18 July 2014; revised 18 August 2014; accepted 16 September 2014

Copyright (C) 2014 by author and Scientific Research Publishing Inc.

This work is licensed under the Creative Commons Attribution International License (CC BY). http://creativecommons.org/licenses/by/4.0/

c) (i) Open Access

\begin{abstract}
Multiple pulmonary nodules on chest x-ray, known commonly as cannon ball secondaries, are the classical presentation of haematogenous dissemination of a malignant tumor to the lungs. This almost always indicates advanced stage of the disease with a very grim outlook in terms of cure or survival. In this report we present a patient with very extensive Cannon Ball Metastases due to advanced colonic malignancy.
\end{abstract}

Keywords

Cannon Ball Metastases, Lung Metastasis, Malignancy

\section{Introduction}

Bilateral Cannon Ball Metastases are seen in advanced malignancy. Such lesions usually suggest poor prognosis. Multiple lung metastases due to colon cancer have been reported in past; however, such extensive and numerous lesions as in our case report are rare.

\section{Case Report}

A 49-year-old male Bulgarian National presented to us with complaints of fever for two days, followed by drowsiness and shortness of breath since few hours. Fever was high grade, 106 deg F; and was associated with chills. He took medications from a local practitioner with no relief. Few hours before coming to hospital, he developed cough with severe shortness of breath and altered sensorium. There was no history of seizures. No headache or vomiting. Past history was significant for presence of Carcinoma Colon. He had undergone Surgery followed by Chemotherapy for the same two years ago. The detailed history and reports were not available as patient and his family were visiting India for a vacation.

On examination, he was drowsy but arousable with a respiratory rate 45/min and use of accessory muscles of 
respiration. Heart rate 156/min, blood pressure 120/80 mm of Hg, oxygen saturation 92\% on room air and temp 106.6 deg F. Examination of chest revealed conducted sounds with bilateral crepitations. In view of impending respiratory failure, he was intubated in the emergency room.

Chest X-ray (Figure 1) revealed nodular lesions involving both lungs, predominantly in mid and lower zones.

CT chest (Figure 2(a) \& Figure 2(b)) bilateral extensive cannon ball lung metastases with mediastinal lymphadenopathy and associated L2 vertebral body metastases.

A diagnosis of systemic metastases with extensive cannon ball lung metastases due advanced carcinoma colon with secondary septicaemia was considered. In view of high grade fever and travel to endemic state, a probability of complicated malaria was also kept. Patient was admitted in ICU and was treated with broad spectrum antibiotics and antimalarials. Patient developed worsening hypotension refractory to inotropes with metabolic acidosis and succumbed to his illness within 24 hours of admission.

\section{Discussion}

Multiple pulmonary nodules seen on plain chest x-ray have a multitude of causes, starting from metastases (cannon ball secondaries), various infections, immunological diseases to arterio-venous malformations [1].

Pulmonary metastases in adults are usually from breast, kidney, gut, testes, head-neck tumors and a variety of sarcomas. The basic sign of haematogenous pulmonary metastases is one or more discrete pulmonary nodules. The nodules are usually spherical and well-defined, but they may be almost of any shape and can occasionally have a very irregular edge, especially in adenocarcinoma [2]. Calcification is very unusual except in osteo/ chondrosarcoma. Secondary deposits can also present as miliary mottling throughout the lung fields or with extensive perihilar spread (lymphangitis carcinomatosa) [3].

There are reports of Cannon Ball Metastases due to colon cancer [2]. It is usually seen in advanced stages of the disease especially when treatment is delayed. Such extensive metastases in patients on regular follow-up and chemotherapy as ours are not usual. It suggests the aggressiveness of the malignancy or there was poor compliance with the treatment. Such numerous and extensive metastases are rare in literature [2].

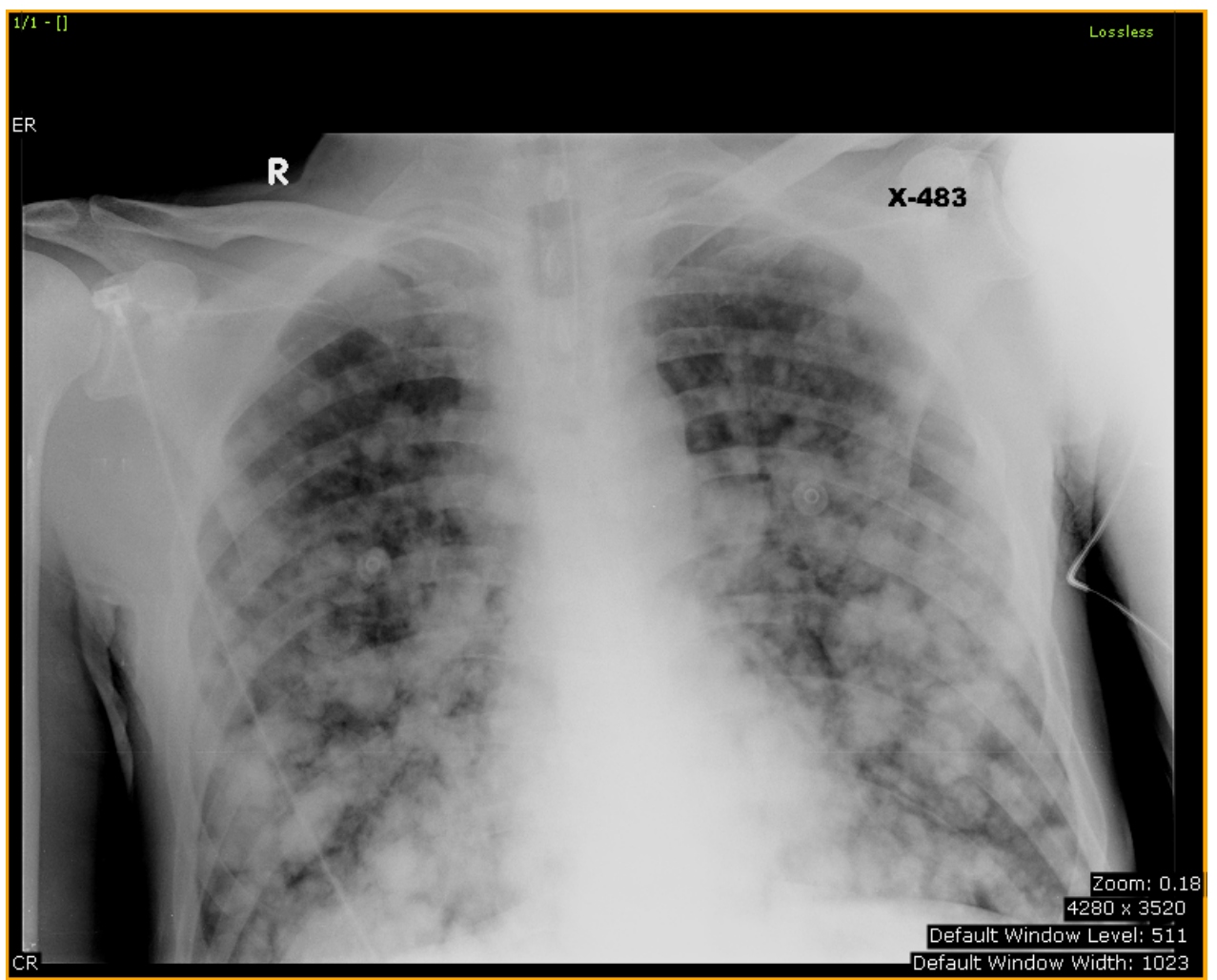

Figure 1. Chest $\mathrm{x}$-ray showing multiple nodular lesions involving both lungs, predominantly in mid and lower zones. 


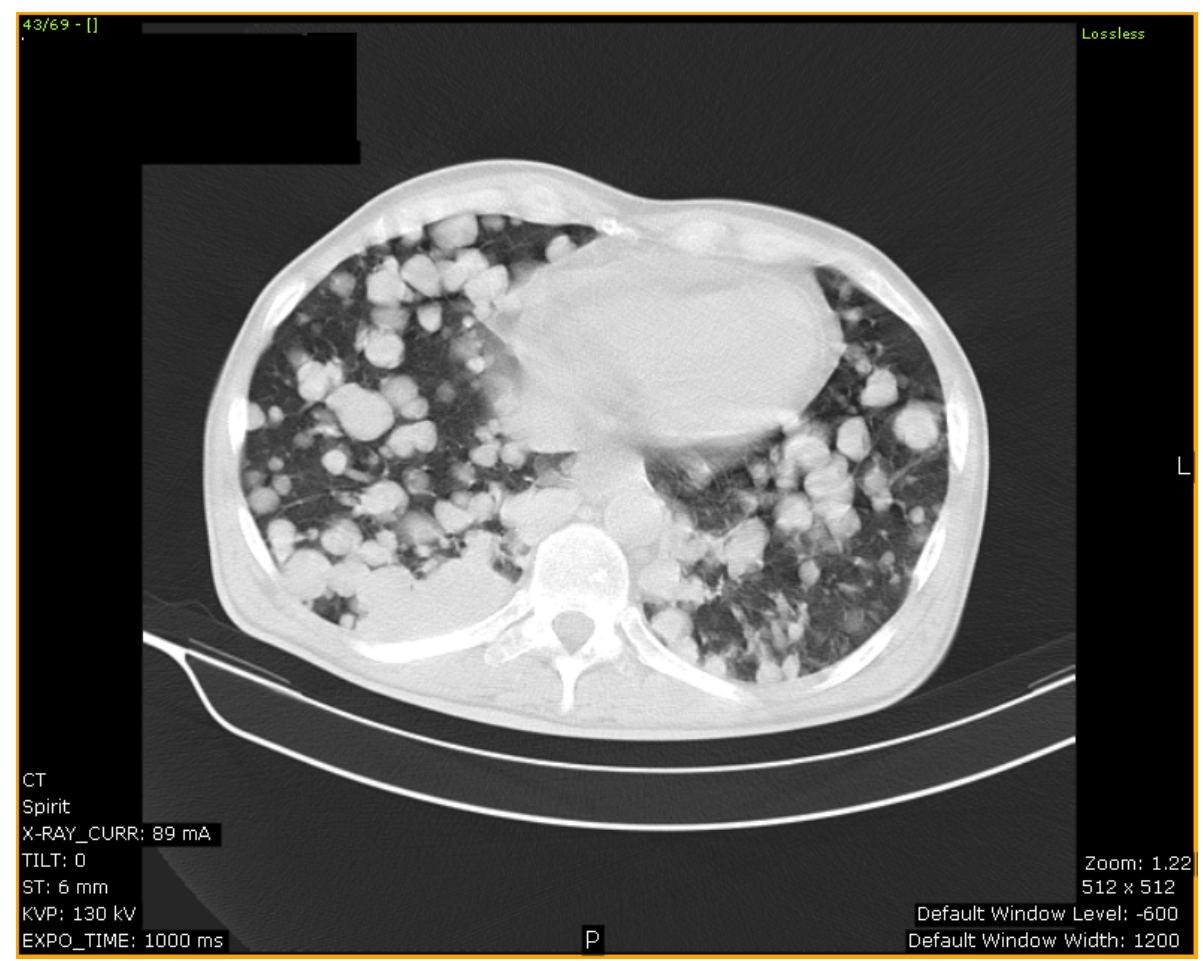

(a)

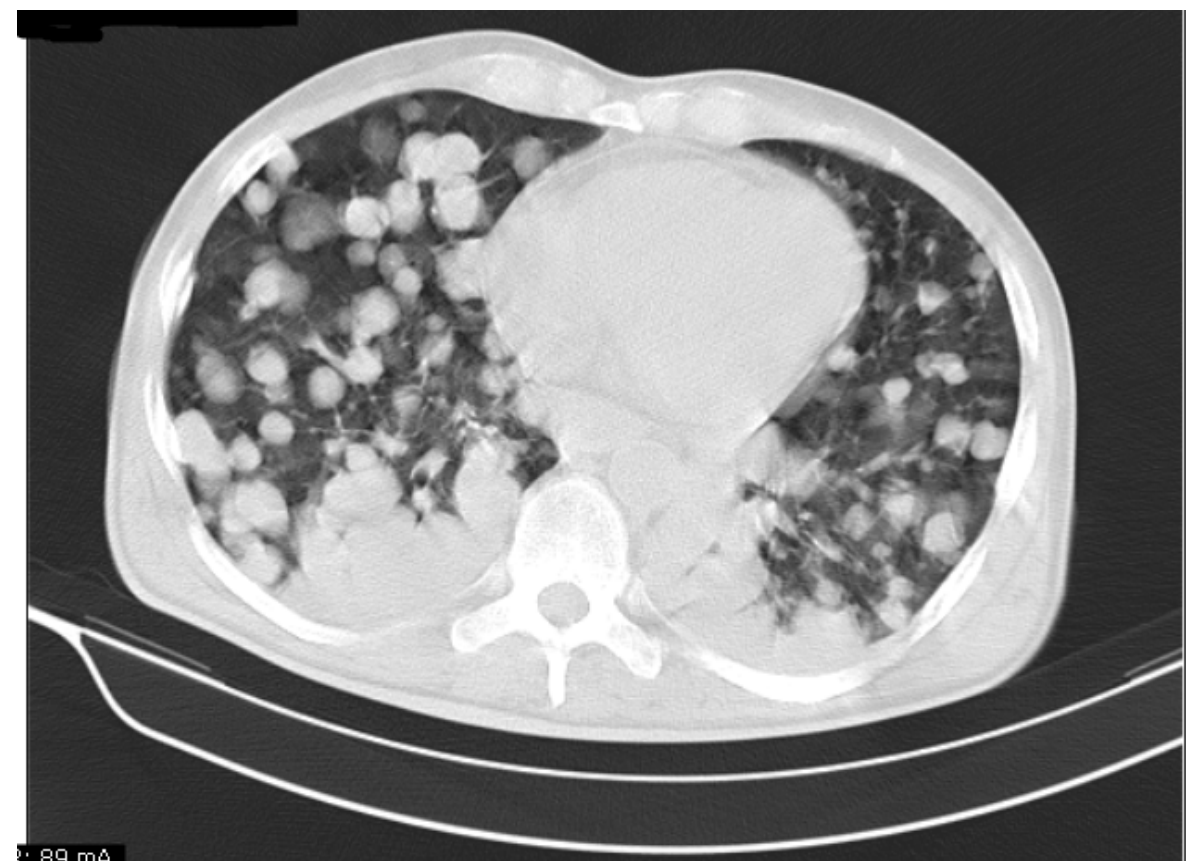

(b)

Figure 2. (a), (b) CT Chest showing bilateral extensive cannon ball lung metastases.

Extensive Cannon Ball Metastases as seen in our case is not much in today's world due to awareness and early diagnosis and management of malignancy. Nabi, G., et al. [4] presented a case report where they had reported a patient with extensive (as our) Cannon Ball Metastases due to carcinoma of prostate. The patient improved after orchidectomy. Cannon Ball Metastases is a sign of advanced malignancy and survival is rare especially in patient like ours where it is due to colo-rectal cancer. 
Nevertheless extensive Cannon Ball Metastases can be found occasionally, especially in advanced malignancy where treatment is either delayed or denied and in such situations, prognosis is very grim.

\section{References}

[1] Chapman, S. and Nakielny, R. (2003) Aids to Radiological Differential Diagnosis. 4th Edition, Saunders-Elsevier, New Delhi.

[2] Armstrong, P. (1997) Pulmonary Neoplasms. In: Grainger, R.G. and Allison, D., Eds., Diagnostic Radiology: A Textbook of Medical Imaging, 3rd Edition, Churchill-Livingstone, Hong Kong, Chapter 20.

[3] Sutton, D. (2001) Radiology and Imaging for Medical Students. 7th Edition, Churchill-Livingstone, New Delhi.

[4] Nabi, G. and Sadiq, M. (2002) Multiple Bilateral Cannon-Ball Lung Metastases from Carcinoma of the Prostate: Orchiedectomy Induced Remission. Medical Journal of Malaysia, 57, 111-113 
Scientific Research Publishing (SCIRP) is one of the largest Open Access journal publishers. It is currently publishing more than 200 open access, online, peer-reviewed journals covering a wide range of academic disciplines. SCIRP serves the worldwide academic communities and contributes to the progress and application of science with its publication.

Other selected journals from SCIRP are listed as below. Submit your manuscript to us via either submit@scirp.org or Online Submission Portal.
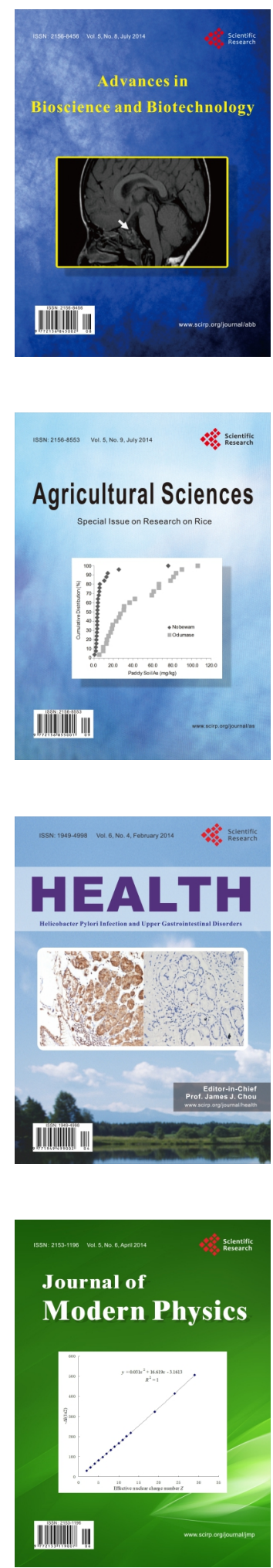
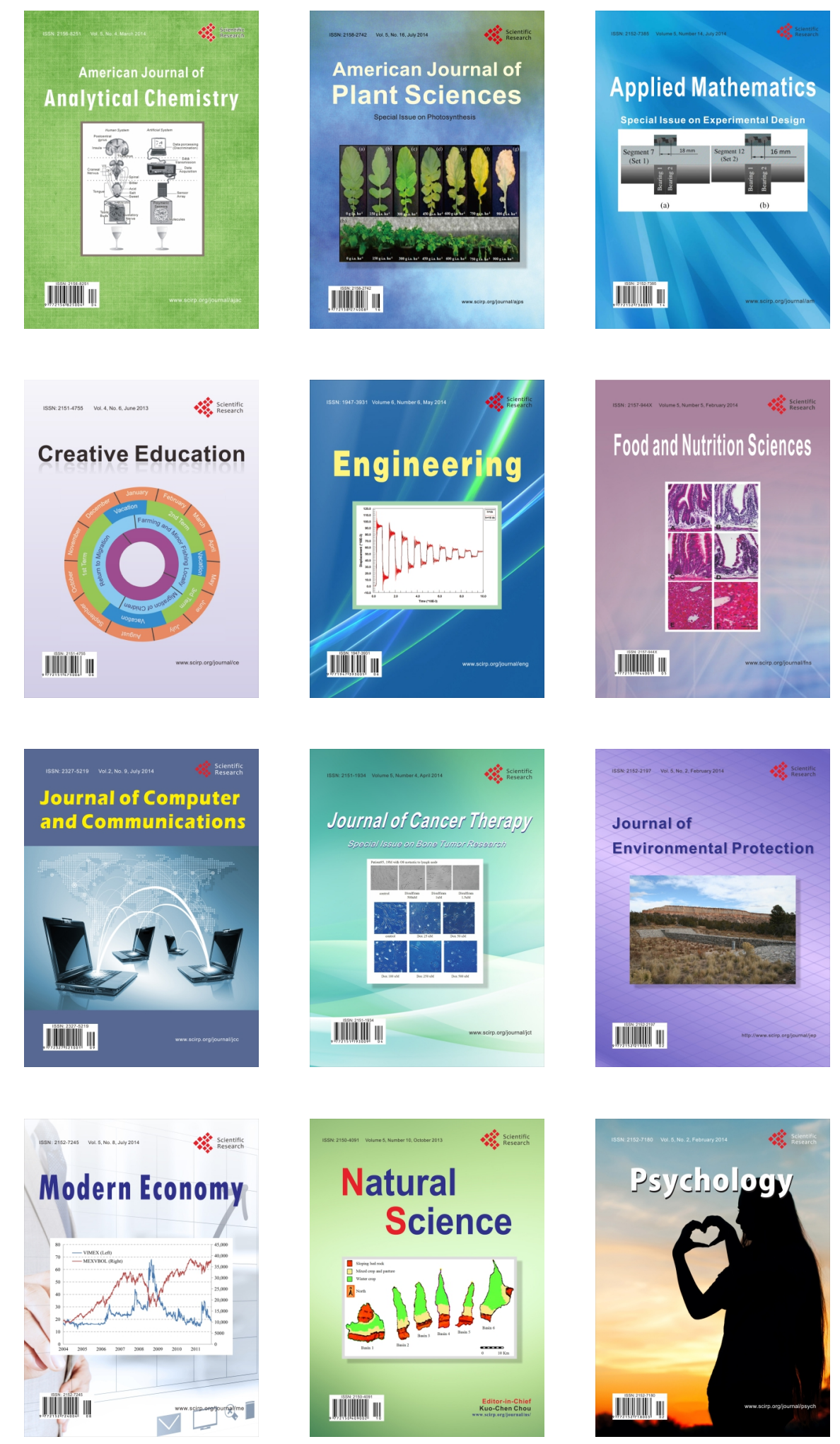